\title{
Changes in Physical Characteristics and Performance of Elite Sailors Following Introduction of a Sport Science Programme Prior to the 1996 Olympic Games
}

\author{
Stephen J. Legg, Hamish W. Mackie* and David A. Slyfield** \\ Department of Management Systems, Massey University
}

\begin{abstract}
A bstract. The objective of this study was to examine changes in sailors' physical characteristics during three different time periods immediately before the $1996 \mathrm{~N} \mathrm{ew}$ Zealand Olympic trials, as a result of a newly introduced sport science programme. Twenty five ( 19 male and 6 female) Olympic development squad members volunteered as subjects and completed fitness tests at different times between A pril 1995 and March 1996 after being administered with individualised physical training programmes. Statistically significant improvements were observed in body weight, sum of skinfolds, flexibility (assessed using a sit-reach test), aerobic endurance (assessed using a maximal effort $2500 \mathrm{~m}$ rowing test) and strength (assessed as the maximum number of pushups, pull-ups, and sit-ups that could be completed in 2 minutes) over the three time periods. Thus, physical training was effective in improving many aspects of sailors' fitness, especially early in the sailing season as a result of pre-season training. Physical performance correlated poorly with both light and heavy wind racing performance. The results suggest that individually tailored training programmes will increase sailing specific fitness. However, it is impossible to know what proportions of racing performance can be attributed to physical fitness, skill, talent, and technology, therefore the effect of physical training on racing performance is difficult to determine.
\end{abstract}

(Appl Human Sci, 18 (6): 211-217, 1999)

Keywords: yachting, physical fitness, sport science, training

\section{Introduction}

The physical demands of Olympic class dinghy sailing

*Present: Department of Health Sciences, Faculty of Health Sciences and Technology, UNITEC

**Present: Centre for Sport Performance, The University of Auckland are unique. To counter the forces of the wind on the sail(s) the sailor must lean out over the windward side of the boat. This activity (hiking) involves quasi-isometric action of the muscles in the anterior side of the body (abdominals, hip and knee extensors especially) and during racing requires strength, endurance and flexibility (Mackie et al., 1999).

There have been a number of studies that have investigated the physical demands of dinghy sailing (Niinimaa et al., 1977; Marchetti et al., 1980; Shepherd, 1990; Le Goff, 1988; Gallozzi et al., 1993; Putnam, 1979; Vogiatzis et al., 1993, 1994; Mackie et al., 1999; Legg et al., 1997; Legg et al., 1999). There are, however, only two previously reported studies of physical training, and the effects of the training on sailors physical ability (Wright et al., 1976; Spurway and Burns, 1993). The physical conditioning programmes that Wright et al. and Spurway and Burns used were specific to dinghy sailing but were not tailored to the needs of each individual, in terms of the class of boat sailed and the weaknesses of each sailor. No attempt was made to relate the improved physical characteristics of the sailors to racing performance. Wright et al. found that the sailor's racing performances improved following the prescribed physical training programme. However, the reasons for the improvements were not clear. Legg et al. (1997) compared the physical performance of 31 elite New Zealand sailors with that of 108 elite sailors from 10 other nations. The New Zealand sailors were lighter and younger than the other sailors and tended to have greater shoulder/arm strength and endurance and were aerobically fitter. The measurements were not repeated at a later date so it was not possible to examine changes in the sailor's physical characteristics.

The aim of the present study was to examine the changes in sailor's physical characteristics during the buildup to the 1996 Olympic games selection trials after being provided with individualised training programmes as part of a newly introduced sport science programme (Legg et al., 1997; Legg and Mackie, 1999, Mackie and Legg, 1999b). The training programmes included strength, endurance and flexibility training and were periodised into off-season, pre- 
season and in-season. A secondary aim was to examine the relationship between sailors' physical characteristics to racing performance.

\section{Methods}

\section{Subjects}

Twenty five ( 19 male and 6 female) Olympic development squad sailors were used as subjects at different times during the period A pril 1995 to March 1996. The subjects consisted of five Laser, four Europe, three Mistral and one Finn sailor, and four 470 skippers, five 470 crew, two Tornado skippers and one Tornado crew.

\section{Study design}

Three periods of time were used to study changes in sailors' physical characteristics. Depending on sailor's availability, different sailors were tested in each of the three time periods. The first group of sailors was tested during April 1995 (end of competitive sailing season) and again during December 1995 (early the next season). Traditionally, sailors are most fit for sailing at the end of the sailing season (March/April) purely as a result of a season of sailing. By testing sailors again near the start of the following season, the effects of pre-season physical preparation (as a result of the newly advised training programme) were noted. The second group of sailors was tested during September 1995 (beginning of sailing season) and again in December 1995 (early but well into the season). This allowed comparisons of sailors physical characteristics as they moved from pre-season training to in-season training. Lastly, The sailors that had been chosen as the 1996 Olympic team were tested during April 1995 (end of season) and again during March 1996 (end of the following season). This comparison allowed sailor's physical fitness to be monitored over two successive seasons during the long-term build-up to the 1996 Olympic games.

\section{Indi viduali sed training programmes}

In general, the underlying pattern of training over the sailing year included strength (weight training), endurance (mostly running, cycling and rowing) and flexibility (mixture of pre and post exercise stretching and whole flexibility sessions) and was periodised into off-season, preseason and in-season. It is difficult to be specific about the individualised training programmes followed by each sailor since at the very high level at which these athletes perform it is essential that the training programmes are highly individual, so by their very nature are determined by the particular needs of both the class of dinghy and the physical characteristics if the individual sailor, including any modifications associated due to injuries. In addition, for competitive reasons some of the sailors were less than willing to divulge the details of their programme arguing that it might provide a competitive advantage to their opposition, particularly in some cases giving them clues to their injuries.

\section{Test protocol}

Physical characteristics were measured using body composition, flexibility, strength and endurance tests. Body composition was determined by recording the sum of skinfolds from eight sites for males and 7 sites for females.

Flexibility was determined using a sit and reach test (Legg et al., 1997). Each subject sat with their legs in front of them with their feet flat against a box approximately 20 $\mathrm{cm}$ in height. The subjects were barefoot and their knees were locked. The best of three measurements from the tips of the fingers to the soles of the feet were recorded, and each attempt was required to be maintained for at least three seconds.

To measure strength, press ups, sit ups and pull ups were used (Legg et al., 1997). When possible a test for isokinetic strength was completed for the quadriceps and hamstrings using a Biodex machine. When performing press ups, the maximum number of continuous, full body press ups were counted (Legg et al., 1997). The body was required to be lowered to a position where the arm was parallel with the floor. The required tempo was one second up, and one second down.

The maximum number of continuous sit ups performed in a two minute period were measured. The hands were held behind the head, feet were anchored, and elbows were required to touch the knees during each repetition. Subjects were advised of 30,60 and 90 seconds so they could pace themselves. The test ceased when the subject could no longer work continuously or at the end of two minutes.

When subjects performed chin ups, an under hand and shoulder width grip was used (Legg et al., 1997). The chin was required to touch the bar to count as a successful repetition, and the body was required to be lowered to a near straight arm position with minimal body swing. The required tempo was 1.5 seconds up and 1.5 seconds down.

When an isokinetic leg strength test was undertaken, angular velocity was set to 30 degrees/sec for three repetitions. The outcome was expressed as peak torque $(\mathrm{Nm})$ for both the quadriceps and hamstring muscles. The single highest peak torques were recorded. The test was preceded with a warm up trial of 10 reps at 180 degrees/ sec.

Not all subjects in each group completed all of the tests. The subject numbers that completed tests are shown in Tables 1-3.

\section{Data processing}

Means and standard deviations were calculated for the outcomes of each test for the initial and final test in the 
three time periods. Paired t-tests were performed on the same sets of data so that differences in sailor's physical characteristics between the initial and final fitness tests could be identified. Because the changes in subjects physical characteristics over time were of primary concern rather than the absolute measures, males and females were grouped together.

Sailors physical characteristics that were measured closest to the Olympic trials (a light weather regatta) during March 1996 were correlated with sailors Olympic trials final ranking in relation to the other sailors used in this study. Sailors physical characteristics were also correlated with the sailors final ranking in the Sail Auckland International Regatta (a moderate/heavy weather regatta) in February 1996. Laser sailors physical characteristics were also correlated with their final ranking in the National Laser Championships held in March 1996. By comparing these results it was determined how closely sailors physical characteristics were related to racing performance in light weather and in windier weather.

\section{Results}

Changes in sailors physical characteristics

Tables 1, 2 and 3 show the mean and standard deviation of sailors physical characteristics in the three groups. In the April-December group (Table 1) there were significant increases in body weight $(2.1 \mathrm{~kg})$, sit and reach (35 mm), pull up (2.2), and sit up scores (13.1). There was a significant decrease in $2500 \mathrm{~m}$ rowing time $(0.7$ decimal minutes). The number of push ups sailors could perform increased (3.9) however this change was not significant.

The September-December group (Table 2) exhibited significant increases in pull ups (3.3) and sit ups (14). Significant decreases were observed in sum of skinfolds $(14.3 \mathrm{~mm}$ ) and push ups (0.5). Mean sit and reach score increased (13.1) and $2500 \mathrm{~m}$ rowing time decreased ( 0.5 decimal minutes), but the changes were not significant. Mean maximum knee extensor torque decreased ( $8 \mathrm{Nm}$ )

Table 1 Mean (standard deviation) data for the physical characteristics of sailors tested between April 95-December 95

\begin{tabular}{lrccc}
\hline & $\mathrm{n}$ & April & December & Difference \\
\hline Body weight (kg) & 7 & $70.2(8.7)$ & $72.1(7.7)$ & $2.0^{*}$ \\
Sum/skinfolds (mm) & 5 & $84.4(32.2)$ & $90.0(29.9)$ & 5.6 \\
$\quad \begin{array}{l}\text { Flexibility } \\
\quad \text { Sit and reach (mm) }\end{array}$ & 9 & $148.3(82.7)$ & $183.3(92.1)$ & $35^{*}$ \\
A erobic Endurance & & & & \\
$\quad$ 2500 m row (dec.min) & 9 & $10.0(1.1)$ & $9.3(0.6)$ & $-0.7^{*}$ \\
Strength & & & & \\
$\quad$ Push ups (No.) & 9 & $25.3(12.2)$ & $29.2(11.8)$ & 3.9 \\
$\quad$ Pull ups (No.) & 11 & $7.1(5.5)$ & $9.3(7.4)$ & $2.2^{*}$ \\
$\quad$ Sit ups (No.) & 9 & $49.1(10.1)$ & $62.2(12.4)$ & $13.1^{* *}$ \\
\hline
\end{tabular}

$*$ - $p<0.05, * *-p<0.01$ (using paired t test). Male:Female ratio $=3.0: 1$.

Table 2 Mean (standard deviation) data for the physical characteristics of sailors tested between September 95-December 95

\begin{tabular}{lcccc}
\hline & $\mathrm{n}$ & September & December & Difference \\
\hline $\begin{array}{l}\text { Body weight (kg) } \\
\text { Sum/skinfolds (mm) }\end{array}$ & 3 & $70.3(5.9)$ & $70.5(6.3)$ & 0.1 \\
$\begin{array}{l}\text { Flexibility } \\
\quad \text { Sit and reach (mm) }\end{array}$ & 8 & $124.4(87.7)$ & $137.5(63.5)$ & 13.1 \\
Aerobic Endurance & & & & \\
$\quad$ 2500 m row (dec.min) & 8 & $10.2(1.4)$ & $9.7(1.1)$ & -0.5 \\
$\quad$ Strength & & & & \\
$\quad$ Push ups (No.) & 8 & $10.2(1.4)$ & $9.7(1.1)$ & $-0.5^{*}$ \\
$\quad$ Pull ups (No.) & 8 & $7.5(5.1)$ & $10.8(7.0)$ & $3.3^{* *}$ \\
$\quad$ Sit ups (No.) & 5 & $41.2(18.4)$ & $55.2(18.8)$ & $14.1^{*}$ \\
$\quad$ Knee ext. (Nm) & 6 & $251.5(87.9)$ & $243.5(75.5)$ & -8.0 \\
$\quad$ Knee flex. (Nm) & 6 & $126.8(39.7)$ & $118.9(33.0)$ & $-7.9^{*}$ \\
\hline
\end{tabular}

$*_{-} p<0.05, * *-p<0.01$ (using paired t test). Male:Female ratio $=2.3: 1$. 
Table 3 Mean (standard deviation) data for the physical characteristics of sailors tested between April 95-March 96

\begin{tabular}{lcccc}
\hline & $\mathrm{n}$ & April 95 & March 96 & Difference \\
\hline Body weight (kg) & 5 & $67.5(10.7)$ & $65.9(9.4)$ & -1.6 \\
$\quad$ Sum/skinfolds (mm) & 6 & $68.0(30.4)$ & $60.5(13.1)$ & -7.5 \\
$\quad$ Flexibility & & & & \\
$\quad$ Sit and reach (mm) & 0 & & & \\
Aerobic Endurance & & & & \\
$\quad$ 2500 m row (dec.min) & 0 & & & \\
$\quad$ Strength & & & & \\
$\quad$ Push ups (No.) & 5 & $25.2(9.3)$ & $25.2(8.8)$ & $2.9^{*}$ \\
$\quad$ Pull ups (No.) & 6 & $9.8(3.2)$ & $12.7(5.2)$ & $5.8^{*}$ \\
$\quad$ Sit ups (No.) & 5 & $41.4(6.5)$ & $47.2(4.4)$ & \\
\hline *-p<0.05 (using paired t test). Male:Female ratio $=2.3: 1$. &
\end{tabular}

Table 4 Correlations ( $r^{2}$ values) between physical performance and racing performance in classes with a reasonable subject size

\begin{tabular}{|c|c|c|c|c|c|c|c|c|c|c|c|c|}
\hline Crew type & $n$ & $\begin{array}{c}\text { Competition } \\
\text { (wind strength) }\end{array}$ & $\begin{array}{l}\text { Body } \\
\text { weight }\end{array}$ & $\begin{array}{l}\text { Sum of } \\
\text { skinfolds }\end{array}$ & $\begin{array}{l}\text { Sit } \& \\
\text { reach }\end{array}$ & $\begin{array}{l}2500 \mathrm{~m} \\
\text { Row }\end{array}$ & $\begin{array}{c}\text { Mainshee- } \\
\text { ting } \\
\text { Power }\end{array}$ & Pull-ups & Push-ups & Sit-ups & $\begin{array}{c}\text { Leg } \\
\text { strength } \\
\text { quadriceps }\end{array}$ & $\begin{array}{c}\text { Leg } \\
\text { strength } \\
\text { hamstrings }\end{array}$ \\
\hline \multirow[t]{2}{*}{470 crew } & 7 & Olympic trials (light) & 0.15 & -0.12 & 0.73 & -0.39 & 0.27 & 0.35 & -0.08 & 0.46 & -0.16 & -0.14 \\
\hline & & Sail Auckland (moderate) & -0.35 & -0.62 & 0.10 & 0.63 & -0.31 & -0.18 & -0.33 & 0.06 & 0.60 & 0.48 \\
\hline \multirow[t]{2}{*}{470 skipper } & 6 & Olympic trials (light) & 0.44 & 0.03 & -0.27 & -0.66 & 0.62 & 0.33 & -0.34 & 0.78 & 0.28 & 0.03 \\
\hline & & Sail Auckland (moderate) & -0.33 & -0.26 & -0.16 & 0.13 & -0.33 & 0.27 & -0.10 & 0.85 & -0.36 & -0.81 \\
\hline \multirow[t]{3}{*}{ Laser } & 6 & Olympic trials (light) & -0.68 & 0.09 & 0.51 & 0.39 & 0.18 & -0.03 & 0.21 & 0.62 & 0.26 & -0.67 \\
\hline & & Sail Auckland (moderate) & 0.56 & 0.22 & 0.03 & 0.05 & 0.62 & -0.70 & -0.43 & -0.53 & -0.61 & -0.98 \\
\hline & & Laser Nationals (moderate) & 0.60 & 0.76 & -0.20 & 0.49 & 0.76 & -0.59 & -0.47 & -0.55 & -0.43 & -0.93 \\
\hline
\end{tabular}

insignificantly while maximum knee flexor torque decreased (7.9 $\mathrm{Nm}$ ) significantly.

Increases in pull ups (2.9) and sit ups (5.8) were the only significant changes in the April 1995-March 1996 group (Table 3). However, flexibility and endurance tests were not carried out for this group. Both mean body weight and sum of skinfolds decreased ( $1.6 \mathrm{Kg}$ and $7.5 \mathrm{~mm}$ respectively) but the changes were not significant.

\section{Relationship of physical characteristics with racing performance}

Poor correlations between physical performance and racing performance were observed in all classes for all of the sailing regattas. The highest correlations $\left(r^{2}=0.85\right.$ and $r^{2}=0.78$ ) were observed in the male 470 skipper between sit up scores and performance in the Sail Auckland regatta and Olympic trials respectively. The Laser class had positive correlations of $r^{2}=0.76$ between sum of skinfolds and Laser Nationals performance and mainsheeting power and Laser Nationals performance. Negative correlations of $r^{2}=0.98$ and $r^{2}=0.93$ were observed between hamstring leg strength and Sail Auckland performance and Hamstring leg strength and Laser Nationals performance respectively.

\section{Discussion}

Changes in sailors physical characteristics

If sailors followed their usual training patterns, then there should have been a decrease in sailing specific fitness over the April-December period. They would be fittest at the end of the sailing season (A pril), then a lack of physical training during off-season and pre-season would mean that their fitness would decrease. The fact that flexibility, endurance and strength scores all improved ( 4 out of 5 significantly) suggests that the prescribed training programmes as part of the sport science programme that was introduced was effective in improving the physical preparation of sailors for the 1995/96 season. The lack of significant change in the mean push ups score, may reflect the sailors tendency to focus on training muscles specific to sailing (e.g. pull ups and sit ups), and neglect those actions that do not relate directly to sailing. If so, this would raise concern as weight training should include antagonist muscle groups as well as agonists to prevent muscle imbalances. The significant increase in body weight and the insignificant increase in sailors sum of skin folds suggest that the sailors experienced an increase in muscle mass as a result of pre-season and early season physical training. 
The results from the group of sailors tested during September 1995 and again during December 1995 provide an indication of the fitness changes that occurred as the sailors moved from pre-season training to in-season training. The significant increase in mean sit-up and pullup scores reflect the increased use of sailing related muscles due to increased sailing time (abdominals for hiking; back, shoulder and arm muscles for pulling ropes). The significant decrease in mean push-up score also reflects the move to increased actual sailing, as the pushup action is not used regularly when sailing. Insignificant change in aerobic endurance was to be expected considering that by December most sailors were likely to be involved in 'maintenance' level off-water training. Although changes in flexibility were insignificant, flexibility would be expected to improve during the sailing season as a result of increased sailing. Significant decreases in sailors' sum of skinfolds and very little change in body weight suggest increased proportions of lean muscle mass, which is also consistent with increased sailing and less emphasis on gym based work outs.

Significant increases in mean pull up and push up scores for the group tested during April 1995 and again during March 1996 (the chosen 1996 Olympic team) reflects increased attention given to physical conditioning since the previous season. Surprisingly, the decrease in sum of skin folds (that usually follows physical conditioning) was not significant. However, subject numbers were generally less for this group of sailors.

In the three subject groups, many of the initial and even final physical performance measures are poorer than those reported by Legg et al. (1997) when males and females were grouped together. However, the subjects in Legg's study had a much higher proportion of male subjects (male:female $=4.8: 1$ compared with 3.0:1, 2.3:1 and 4.5:1 in the April-Dec, Sept-Dec and April-March groups respectively). Therefore, one would expect the scores reported by Legg et al. to be superior. Some of the fitness related scores in the present study were however better than those reported by Legg et al. despite the greater proportion of females in the subject groups. Superior 2500 $m$ rowing times were observed in the final results of the April-December group and the September-December groups. A greater number of sit-ups were observed in the final results of the April-December group and a greater number of pull-ups were observed in the final results of the A pril 95- March 96 group. These findings suggest that the recently prescribed physical training programmes are improving the fitness of Olympic class sailors.

The subjects adherence to the exercise programmes was not controlled or monitored. For this reason the changes in subjects physical characteristics cannot definitely be attributed to the exercise programmes, but rather to the advice that the subjects received regarding physical preparation.
The physical performance tests used in the present study were based on those that were first employed by a US national coach during the late 1980 s as part of his consultancy advice to a number of national and provincial sailing teams around the world (Legg et al., 1997). The tests were based upon those used for selection of military personnel. The push-up and pull-up tests are a measure of shoulder/arm strength and endurance. The extent to which the same muscle groups are used in dinghy racing is not clear. The sit-up test was used in the present study because it had been used in an earlier study (Legg et al., 1997). As a test of abdominal strength and endurance it has severe limitations since the hip flexor muscles are a prominent determinant of the performance of the test. A test which more closely simulates the hiking action of sailing would be more appropriate. Cycling or running tests would be inappropriate. The maximal effort rowing test is considered to be a realistic and appropriate way of assessing aerobic power in dinghy sailors as it utilise the muscles in the lower and upper body and involves dynamic flexion and extension of the trunk-all of which is appropriate in varying degrees as a simulant of the physical activities in Olympic class dinghy racing. The face validity of the tests used in the present study to assess the physical abilities of the sailors is questionable and has been objectively examined by Mackie et al., 1999 based on retrospective postural and temporal analyses of body postures during simulated on-water racing. The latter study has provided a much improved and relevant set of physical performance tests for sailors and is reported in a book of the proceedings of a Sailing Science Symposium held in Glasgow, Scotland in J uly 1999 (unpublished the time of writing).

Relationship of physical characteristics with racing performance

The fact that there were poor correlations between physical characteristics and racing performance is understandable given that the Olympic trials were held in predominantly light weather conditions. In light conditions the sailor mainly sits on the side of the boat which is not very physically demanding. However, one would expect the improved correlations in the windier Sail Auckland and Laser Nationals. Even in windy conditions, skill and tactics play a large part in overall performance in a yacht race, and these factors cannot be controlled. It is impossible to know what proportion of a successful sailing performance can be attributed to physical fitness. Also subject numbers were small due to necessary divisions by class making correlations difficult. A better indication of the relationship between physical performance and racing performance may be possible by using bigger subject sizes and a greater number of racing results.

Legg et al. (1997) also examined the relationship between physical performance and racing performance. No 
identifiable relationships were found except that Older sailors tended to have better racing performances suggesting that experience contributes significantly to racing performance. Poor subject numbers in each class and other factors such as skill and talent, again, may have been reasons for such poor relationships.

Only two other studies have attempted to examine the relationship between a sailor's physical characteristics/ capabilities and their on-water sailing performance (Niinimaa et al., 1977; Plyley et al., 1985). Both studies, as well as that of Legg et al. (1997), compared the biological characteristics of sailors with an overall ranking or rating of the sailor's sailing ability derived either from the team captain, the other sailors in the team (Niinimaa et al., 1977) or the national coach (Plyley et al., 1985; Legg et al., 1997). Plyley et al. found that body mass was well matched to sailing performance ranking for most of the Olympic classes of vessels and that flexibility gave a competitive advantage in the Soling class and that hand grip strength helped in the Flying Dutchman class. Niinimaa et al. (1985) showed that in high wind conditions there was a competitive advantage for muscular strength tolerance of anaerobic effort and absolute aerobic power as well as balance and resistance to mental fatigue. Whilst the latter topic is the subject of a separate study by the authors of the present study, Shephard (1990) has suggested that the aerobic power may serve as a marker for body mass and thus the ability to counterbalance the boat. Niinimaa's findings are similar to those of the present study in that the correlations were generally higher in windier conditions. The present study is, however, the first to explore the relation between physical characteristics and race performance using actual race rankings rather than rankings based upon the subjective judgement of an independent (though usually expert) ranker.

\section{Conclusions}

The introduction of individualised training programmes to members of the $\mathrm{New}$ Zealand Olympic development squad has been effective in increasing many of the sailor's physical capabilities at different stages of the training year. Significant increases in various physical capabilities were observed in the April-December, September-December and April 96-March 96 groups. Some of the improvements were greater than the results of the same activities previously reported even though the proportion of females in the subject groups were larger than the previous study. The improvements in physical attributes are a result of the advice the subjects received rather than the training programmes themselves, as adherence was not controlled. Physical performance was poorly related to racing performance. This is understandable since the racing performances were during light wind conditions where racing is not particularly physically demanding. However, poor correlations were also observed when the results from windier races were used. It is impossible to control for sailor's skill and tactical ability, which counts for a large part of the overall performance in Olympic yacht racing. Greater numbers of subjects and race results would provide a better indication of the true relationship between physical performance and racing performance.

Acknowledgements. This study was funded by the Hillary Commission for Sport, Fitness and Leisure with support of Sport Science New Zealand. The Authors gratefully acknowledge the support of Peter Lester, Hamish Wilcox and Craig Gilberd from Yachting New Zealand, and the cheerful participation of the sailors.

\section{References}

Gallozzi C, Fanton F, De Angelis M, Dal Monte A (1993) The energetic cost of sailing. Medical Science Research 21: $851-853$

Le Goff P (1988) Biomechanics of the lumbar spine in sailing. Revue du Rhumatisme 55 (5): 411-414

Legg SJ , Mackie HW (1999) Change in knowledge and reported use of sport science by elite New Zealand Olympic Class sailors (submitted)

Legg SJ, Mackie HW, Smith P (1999) Temporal patterns of physical activity in Olympic yacht racing. Journal of Sports Medicine and Physical Fitness (in press)

Legg SJ , Miller AB, Slyfield D, Smith P, Gilberd C, Wilcox $H$, Tate C (1997) Physical performance of elite New Zealand Olympic class sailors. The J ournal of Sports Medicine and Physical Fitness 37 (1): 41-49

Legg SJ , Smith PA, Slyfield D, Miller AB, Wilcox H, Gilberd $C$ ( 1997) Knowledge and reported use of sport science by elite $\mathrm{N}$ ew Zealand Olympic Class sailors. J ournal of Sports Medicine and Physical Fitness 37: 215-217

Mackie HW, Legg SJ (1999a) A preliminary quantitative assessment of the force demands in laser racing. J ournal of Science and Medicine in Sport 2 (1): 78-85

Mackie HW, Legg SJ (1999b) Development of knowledge and reported use of sport science by elite New Zealand Olympic class sailors. Appl Human Sci 18 (4): 125133, 1999

Mackie HW, Sanders RH, Legg SJ (1999) Physical demands in Olympic yacht racing. J ournal of Science and Medicine in Sport (in press)

Marchetti M, Figura F, Ricci B (1980) Biomechanics of two fundamental sailing postures. J ournal of Sports Medicine and Physical Fitness 20: 325-332

Niinimaa V, Wright G, Shephard RJ, Clarke J (1977) Characteristics of the successful dinghy sailor. J ournal of Sports Medicine and Physical Fitness 17 (1): 8396

Plyley MJ, Davis GM, Shephard RJ (1985) Body profile 
of Olympic class sailors. Physician in Sport and Medicine 13 (6) : 152-169

Putnam CA (1979) A mathematical model of hiking positions in a sailing dinghy. Medicine and Science in Sports 11 (3): 288-292

Shephard RJ (1990) Sailing. In Reilly T ed. Physiology of sports. E.\& F.n. Spon. London

Spurway NC, Burns R (1993) Comparison of dynamic and static fitness-training programmes for dinghy sailors-and some questions concerning the physiology of hiking. Medical Science Research 21: 865-867

Vogiatzis I, Roach NK, Trowbridge EA (1993) Cardiovascular, muscular and blood lactate responses during dinghy 'hiking'. Medical Science Research 21: 861-863
Vogiatzis I, Spurway NC, Wilson J (1994) On-water oxygen uptake measurements during dinghy sailing. J ournal of Sports Sciences 12: 153.

Wright G, Clarke J, Niinimaa V, Shephard RJ (1976) Some reactions to a dry-land training programme for dinghy sailors. British J ournal of Sports Medicine 1: 4-10

Received: May 6, 1999

Accepted: August 20, 1999

Correspondence to: Stephen J. Legg, Department of Management Systems, Massey University, Palmerston North, New Zealand

e-mail: s.j.legg@massey.ac.nz 